to render assistance to the biologist of supreme importance. "The amount and direction of the abnormality will be indicated if this [abnormal] frequency-curve can be split up into normal curves." Analysis would in this way give us information which we could perbaps not even guess at.

I agree with Prof. Karl Pearson that "resnlution into two" will be sufficient. The stress of natural selection at any moment must always be between the best and the next best.

In tolerably simple cases $I$ have no doubt that the result of Prof. Karl Pearson's labours will be to throw great light on the matter. In more complicated ones we must look for some disappointment in view of "the great variety of solutions which may be suggested" (p. 106). And the tentative discovery of "componen normal curves" seems likely to be fallacious (p. 90).

(I4) I think it is important to insist that the importance of Prof. Weldon's present results has reference to the stalility prob'em. $\mathrm{He}$ is fully aware of thi; fact when he says that "they cannot be expected to hold in cases of rapid change such as those induced artificially by selectiın under domestication, or naturally by rapid migration or oth $\sim \mathrm{r}$ phenomena resulting in a rapid change of environment." These will lead to abnormal frequency curves.

(15) A few remaining points in Prof. Weldon's paper deserve some remarks.

I entirely agree with him in minimising the value of "sporis" in evolution. As against Nägeli and his followers, I see no ground for believing in any innate progressive tendency in organisms. When the organism is in stable relation with its environment it will continue so indefinitely. That is the conclusion I deduce froin the flora of Egypt, and other facis which have been cited of the same kind. Prof. Weldon seems to me to have supplied this posilion with a most important proof by estahlishing the "selective destruction" of variarions aberrant from the mean specific form. When the environment varies, stability is destroyed; but it will be ultimate'y reestablished, though with a different centre, by the operation of natural selection. The result is that the organism has undergone some permanent degree of change. As I conceive the process, it is one of continuous adjustment of "sli, ht" variations on one side and the other. But it is important to keep in view that variation in the environment stimulates the variation in the organism which supplies the ultimale material for adjustment. That the amount of the adjustment at any moment is slight is not incompatible with its amounting to almost anything we like in the aggregate, if sufficient time be allowed. We might as well deny that a curve can be built up from its infinitesimal elements.

The value in this respect of sports may be easily overrated. It appears to me that generally, so to speak, they attempt too much and overshoot the mark. The improbability of a casual sport being exactly what is wanted to bring the organism into an advantageous relation to the environment at any particular juncture seems to me very great. That such a thing may occur is not denied, but it can harilly be more than a "fluke."

(16) This is confirmed by the fact that in the vegetable kingdom sports are rare, and they seem to have little power of holding their own in competition. I instanced the cases of the occurrence of copper-coloured and lacintate foliage in many trees, as well as the occurrence of varieties with weeping and fastigiate habit. It is well known that to some extent these are perpetuated by seed. But the existence of such forms would undoubtedly be transient if it were not for their perpetuation as curiosities under cultivation.

(17) In museums it is usual to attempt the representation of the mean specific form. The association of str kingly aberrant specimens is interesting and often suggestive. But I do not see that they illustrate more than the possibilities of variation and the fact that it may be disc mntinuous.

(I8) I placed upon the table plants of the feral type and of a recent cultivated form of Cineraria cruenta from the Canaries. The difference in habit and in the form and colsur of the flowers was enormous. This has undoubtedly been brought about by human selection. As far as is known it has been ac. complished by the gradual accumulation of small variations. The huriculturist has not troubled himself about the foliage, which, though more luxuriant, has remained practically unchanged. But it must not be assumed that it is unchangeable. In the case of the Chinese primrose, the feral form froin north. west China, for which we are indebied to Dr. Henry, has palmatifid leaves rounded in outline; but the distal lobes are occasionally lengthened out. The horticulturist, as a matter of fancy, working on this, has now split the type into two races, one of which has palmatifid and the other pinnatifid leaves. Many botanists would, undoubtedly, if they did not know their history, assign to such a different specific rank.

(I9) I am not sure that I quite understand Prof. Weldon when he says that "the statistical method is the only one at present obvious by which [the Darwinian] hypothesis can be experimentally checked." In the first place, I should myself hardly call it experimental at all. In the next place, though I think it will throw important light on the stability problem, in the important cases where evolution is actually taking place, the mathematical analysis appears to me to be beset with very great difficulties. We must not, therefore, expect too much from it.

(20) On the other hand, museums, as at present organised, do not help very much the study of evolution. In the case of plants, I doubt if herbaria will ever he able to present material in a sufficiently compendious or complete form to be of much use. The study, however, of extensive series of a few species of insects ranging over the whole of a large geographical area, such as Mr. Elwes has brought together in the case of butterflies, must, it seems to me, afford most important material for future discussion.

Royal Gardens, Kew, March Io.

\section{Do Plants Assimilate Argon?}

IT is a well-known fact that some plants are able to assimilate nitrogen from the atm sphere and form compounds. Now, as argon cannot be induced-at least up to now--by any known process of inorganic chemistry or physical science to enter into a combination with one or more of the known elements, it occurred to me whether that peculiar power which produced the cell is not able to form combinations with argon. The experiment to grow suitable plants in an atmosphere of pureargon, or argon mixed with pure oxygen, on a bed of pure sand, \&c., would easily settle the question.

If this experiment has not yet been made, perhaps you will find space in your paper for the above few lines.

Essen-Ruhr, March 6.

E. BLAss.

THE first thing is obviously to find whether there is any argon in a nitrogenous vegetable; and experiments are now nearly completed in my laboratory to see if nitrogen obtained from peas contains any argon. Similar experiments are being made with nitrogen from mice. In a few days I shall know the results. But this is, of course, on the assumption that the process which liberates nitrogen also liberates argon; and it is by no means certain. It should be remembered that argon and nitrogen have absolutely no similarity, and that their occurrence together in air is a pure accident, due to the inertness of both.

March Io.

W. RAMSAY

\section{The Measurement of Pressures in Guns.}

IN a paper "On Methods that have been adopted for Measuring Pressures in the Bores of Gun:" (Report of the Briti-h Association, 1894), Captain Sir A. Noble has remarked that it seems to him "that there is no method so satisfactory, de-pite its attendant labour, as that of making the projectile write its own story" (p. 540). That might be sufficient for smooth bore guns, where there was little or no friction in the bore, but it is quite unsatisfactory when applied to rifled guns, and especially B.L. guns.

The two methods of experimenting now in use employ the pressure gauge and the chronograph, both of which we will, for this occasion, suppose perfectly accurate. The pressure gauge measures directly the pressure of the powder gas $\mathrm{P}$, the quantity wanted. The chronngraph will measure $P$, the same pressure of the powder gas, minus $F$, the resistance offered to the motion of the shot by the rifling, the friction of the driving-band, \&c., $=\mathrm{P}-\mathrm{F}$, where $\mathrm{F}$ is often very great. The difficulty $\mathrm{i}$; to see how these two different processes can confirm one another, as $\mathrm{F}$ is unknown and of great importance.

The only satisfactory method of determining the maximum pressure of powder gas at any point in the bore of a rifled gun is to measure it directly, by the pressure gauge, which requires many precautions to be taken, or by some other more simple method.

Horncastle, March 9.

NO. I 324 , VOL. 5 I] 